\title{
Outcomes from a National Multispecialty Palliative Care Curriculum Development Project
}

\author{
DAVID E. WEISSMAN, M.D., ${ }^{1}$ BRUCE AMBUEL, Ph.D., ${ }^{1}$ \\ CHARLES F. VON GUNTEN, M.D., Ph.D., ${ }^{2}$ SUSAN BLOCK, M.D., ${ }^{3}$ \\ ERIC WARM, M.D., ${ }^{4}$ JAMES HALLENBECK, M.D., ${ }^{5}$ ROBERT MILCH, M.D., ${ }^{6}$ \\ KAREN BRASEL, M.D., ${ }^{1}$ and PATRICIA B. MULLAN, Ph.D. ${ }^{7}$
}

\begin{abstract}
Background: In 1998 we completed a successful regional pilot project in palliative care curriculum development among 32 internal medicine residency programs recruited from the midwestern United States. Between 1999 and 2004 this project was expanded to include 358 U.S. programs, from four specialties, based on new training requirements in internal medicine, family medicine, neurology, and general surgery.

Objective: To assess the 1-year outcomes from residency programs participating in a national multispecialty palliative care curriculum development project.

Measurement: Outcome data obtained from residency programs' responses to a structured progress report 12 months after enrolling in the project and from published residency project reports.

Results: Three hundred fifty-eight residency programs, representing $27 \%$ of all eligible training programs in the four specialties, participated in the project. Outcome data was available from 224 residencies $(63 \%)$. Most programs started new teaching in pain, nonpain symptom management, and communication skills. More than $50 \%$ of programs integrated palliative care topics within established institutional grand rounds, morbidity/mortality conferences or morning report. More than $70 \%$ of internal medicine and family practice programs began new direct patient care training opportunities utilizing hospitalbased palliative care or hospice programs. New faculty development initiatives and use of quality improvement projects to drive curriculum change were reported in less than $50 \%$ of programs.

Conclusions: Focused short-term instruction in palliative care curriculum development, in a diverse group of residency programs, is feasible and associated with significant curriculum change.
\end{abstract}

\footnotetext{
${ }^{1}$ Medical College of Wisconsin, Milwaukee, Wisconsin.

2San Diego Hospice \& Palliative Care; University of California, San Diego, San Diego, California.

${ }^{3}$ Dana-Farber Cancer Center, Boston, Massachusetts.

${ }^{4}$ University of Cincinnati, Cincinnati, Ohio.

${ }^{5}$ Stanford University, Palo Alto Veterans Hospital, Stanford, California.

${ }^{6}$ The Center for Hospice and Palliative Care; State University of New York at Buffalo, Buffalo, New York.

${ }^{7}$ University of Michigan Medical School, Ann Arbor, Michigan.
} 


\section{INTRODUCTION}

$\mathbf{E}^{\mathrm{B}}$ FFORTS TO IMPROVE palliative care training for physicians-in-training has been a priority in United States medical education for only the past 10 years. ${ }^{1}$ Although palliative care topics, particularly the ethics of end-of-life care, have been widely instituted in undergraduate preclinical education, little has been instituted in the graduate training programs in which physicians learn the skills they will use in practice. ${ }^{2-4}$ A major step forward was the first graduate training requirements specific to palliative care by a major medical specialty, internal medicine, in 1997. Since then, palliative care requirements have been added to a small number of other residency and fellowship programs. ${ }^{5}$

Many palliative care curriculum projects have been reported in the past 10 years, largely restricted to single residency programs. ${ }^{6-16}$ However, large-scale efforts, providing coherent and comprehensive training across medical specialties, are clearly needed. In 1998 we initiated a pilot project to stimulate curriculum development among 32 internal medicine residency programs recruited from the midwestern section of the United States, promoting the best available educational methods for palliative care training. After 1 year, $78 \%$ of these programs were still engaged in curriculum development and reported progress in seven key outcomes: pain assessment, pain management, non-pain symptom management, communication skills, clinical training experiences, teaching conference integration, and faculty development. ${ }^{17,18}$ Based on these encouraging results, the project was expanded to a national cohort of internal medicine residency programs starting in 1999. Over the next 5 years, in response to demand and new training requirements, enrollment was expanded to include family medicine, neurology, and general surgery residency programs, as these specialties adopted their own palliative care training requirements. ${ }^{19}$

The goal of the expanded national project was to recruit $350-400$ residency programs to:

- Start/expand teaching in pain and symptom management.

- Start/expand interactive palliative care communication skills training.

- Start/expand clinical care training opportunities in palliative care/hospice to reinforce di- dactic training and afford opportunities for clinical practice.

- Integrate palliative care content into routine educational conferences.

- Start/expand palliative care faculty development initiatives.

- Use quality improvement principles to encourage new educational initiatives.

This report provides outcomes from the residency programs that participated in this curriculum development project. We describe the extent of curriculum change achieved across and within four different specialties. The study questions include:

1. What is the feasibility and impact of a focused educational intervention on subsequent palliative care teaching practices?

2. To what extent do the strategies and findings from one medical specialty apply to other specialty-focused residency programs?

3. What is the distribution of reforms achieved among palliative care educational domains?

\section{METHODS}

This project was conducted as a prospective, multispecialty, interinstitutional study, designed to assist residency directors in enhancing palliative care teaching within their residency program. The project was structured around the following steps: recruitment, needs assessment, 2-day conference, 1-day follow-up conference, and mentoring (Table 1). The project was reviewed and approved by the Medical College of Wisconsin Institutional Review Board.

\section{Recruitment}

Recruitment efforts included eliciting the support of medical specialty leadership, as well as recruitment directed to residency programs within the specialties. The four oversight specialty associations (American Board of Internal Medicine, American Academy of Neurology, American College of Surgeons, and the Society of Teachers of Family Medicine) were contacted and agreed to assist in recruitment by mailing recruitment packages to program directors with a cover letter of support, and/or advertising the project 
Table 1. Project Steps and Rationale

Recruitment process

Obtain support from national residency organizations to participate in recruitment process.

Rationale: increase the potential for project buy-in from residency program directors.

Needs assessment

a) Program director and senior resident complete independent curriculum review.

Rationale: increase validity of curriculum review process and bring resident "voice" into the project.

b) Invite all residents and teaching faculty to complete 36-item knowledge and self-comfort-confidence surveys.

Rationale: increase tension for change by demonstrating knowledge deficits.

Two-day conference

a) Participation by senior residents with their program directors.

Rationale: increase resident buy-in to curriculum reform process and awareness of career opportunities in palliative care.

b) Private feedback of needs assessment and knowledge test data to individual program directors.

Rationale: increase tension for change for residencies-demonstrate areas of strength and weakness that are program specific.

c) Exclusive use of small group interactive teaching.

Rationale: opportunity for palliative care educators to role model optimal teaching techniques.

d) Teaching modules: Pain, Giving Bad News, and Goal Setting communication skills.

Rationale: these are the most basic elements of improving clinical care in palliative care.

e) Teaching module: Clinical experiential opportunities in palliative care.

Rationale: increase awareness of opportunities to utilize clinical teaching as an essential adjunct to didactic and small group teaching.

f) Teaching module: Basics of Instructional design.

Rationale: acquaint attendees with alternative teaching formats besides lecture, especially for attitude-based content domains.

g) Teaching module: Faculty development.

Rationale: encourage faculty development as key aspect of palliative care curriculum reform.

h) Scavenger hunt for educational resource material

Rationale: Provide opportunity for attendees to review all of the educational material provided as take-home resource material.

Follow-up conference

Presentation of residency progress reports with opportunity for publication.

Rationale: reinforce enthusiasm for continuing curriculum reform; opportunity for program directors to obtain academic credit for curriculum reform.

Mentoring

Contact between faculty mentor and program director following two-day conference.

Rationale: provide support and encouragement to program directors; discuss barriers to implementation and seek alternative approaches; encourage participation in the 1-day conference; encourage completion of progress report.

through organizational communication vehicles. Residencies were recruited into 12 sequential cohorts over the 5 years of the project; all cohorts except one had a target enrollment of 30 residencies. Cohorts 1-2 were exclusively for internal medicine; both internal medicine and family medicine were recruited for Cohorts 3-6. Cohort 7 was exclusively for neurology programs and Cohort 8 was a pilot cohort for surgery residencies, with only 8 programs recruited to test new materials developed for a surgical audience. Cohorts 9-12 contained programs from all four specialties.

Required conditions for participation included: a signed commitment letter from the Department Chair; agreement to complete baseline assessments, to send a team to participate in a 2-day training workshop, and to complete a 12-month progress report. The residency programs were responsible for travel costs and a conference registration fee.

\section{Needs assessment}

Residency directors and a chief resident independently completed a written review of current curriculum offerings in palliative care. All residents and faculty were asked to complete a 36item knowledge assessment and a self-confidence and comfort survey regarding their palliative care skills and attitudes. ${ }^{20-22}$

\section{Two-day conference}

A team from each residency program, comprised of the program director or designee, 1-2 additional faculty, and a senior resident, attended a 2-day workshop with other residency teams from their assigned cohort. Each program received extensive education resource material for use in curriculum development (Table 2). During the conference, to enhance awareness of the variety of educational resources provided to the res- 
Table 2. Educational Resource Material Provided to Residency Programs

Conference Syllabus. Teaching resource material used during the 2-day conference containing examples of teaching objectives, lesson plans, content outlines, pedagological methods, palliative care educational and clinical resources, and four quality improvement projects.

Improving End of Life Care: A resource guide for physician education. Weissman DE, Ambuel B and Hallenbeck, J. Medical College of Wisconsin, 2001. Contains learning objectives, content outlines, pre-tests, role-playing scenarios, small group exercises, and educational references. <www.mcw.edupallmed $>$ Improving End of Life Care: A Faculty Development Resource Book. Weissman DE. Medical College of Wisconsin, 2000.

Communication Skills for the End-of-Life Educator. Weissman DE and Biernat K. Medical College of Wisconsin, 1998. Package contains a trigger video of common palliative care encounters, lesson plans, content outlines, slide sets, learner evaluation materials. <www.mcw.edu/pallmed $>$

Medical Guidelines for Determining Prognosis in Selected Non-Cancer Diseases, 2nd ed. Alexandria, VA: National Hospice and Palliative Care Organization, 1996.

Fast Facts and Concepts provided by weekly email; available at <www.eperc.mcw.edu> Fast Facts were originally designed by Dr. Eric Warm during his work as a residency project participant during the pilot phase of this project. $^{27}$

idency teams, a scavenger hunt was conducted; attendees were asked to locate 16 different educational products within the resource material. One residency program, from those that submitted correct scavenger hunt answers, was selected at random to receive a $\$ 1000$ financial stipend for a 2-day visiting preceptorship to one of three palliative care programs directed by program faculty.

The conference format consisted of six smallgroup training sessions attended in rotation by all faculty participants (Table 3). The focus of the six sessions included the following topics: Pain Management; Communication Skills I: Giving Bad News; Communication Skills II: Goal Setting and Do-Not-Resuscitate (DNR) discussion; Clinical Experiences; Instructional Design; and Faculty Development. Each session included learning objectives, review of best practice educational strategies, and demonstration of educational techniques. An additional training session was attended solely by residents to allow discussion of resident-specific issues in palliative care while their faculty attended the faculty development session. Within the most appropriate session, attendees were introduced to one of four educational quality improvement projects. Each project was designed for a chief resident to collect data from 5-10 charts, data that could be used to demonstrate the need for changes in palliative care practice behavior: (1) pain assessment documentation; (2) analgesic prescribing; (3) advance care planning; and (4) hospice referrals. The teaching faculty for the 2-day conference were consistent across the 12 cohorts except for one faculty change starting with Cohort 5.

\section{One-day follow-up conference}

Six to 9 months after the 2-day conference, an optional 1-day meeting was held for programs to review their progress, discuss barriers, and review additional requested educational methods obtained through a preconference needs assessment sent to all programs. At the end of the conference, participants had an opportunity to review and update their initial Action Plan. Participants were invited to draft a structured progress report, using a suggested template, suitable for presentation at the conference and for publication. ${ }^{23-26}$

\section{Structured mentoring}

A set of strategies was incorporated into the training program to provide a structured mentoring experience. At the end of each of the six training sessions during the 2-day conference, residency teams worked to identify strengths and gaps in their current training, and plan new curriculum initiatives. An additional 60 minutes of scheduled time was included for curriculum planning at the end of each day. To support the planning process, each residency program director met privately with the project evaluation specialist to receive a customized report detailing results from their previously submitted needs as- 
Pain Management

Review common housestaff barriers to providing good pain management.

Learn three educational methods for teaching and evaluating pain assessment and treatment.

Learn different education methods for teaching: (a) analgesic pharmacology and (b) assessing addictiondifferentiating from pain.

Review educational resource material for pain education.

Communication Skills I

Learn three teaching strategies for giving bad news.

Learn how to incorporate personal reflection into communication skills teaching.

Plan a Giving Bad News simulated teaching exercise.

Review education resources for communication skills.

Communication Skills II

Learn steps in initiating a discussion of goal setting and treatment withdrawal.

Learn how to structure a teaching program focused on goal setting and DNR orders.

Learn how to incorporate personal reflection into communication skills teaching.

Plan a simulated teaching session on goal setting and DNR orders.

Clinical Experiences

Learn options for supervised clinical experiences in end-of-life care.

Learn how to utilize traditional educational formats to include greater EOL emphasis (e.g., grand rounds, tumor board, morning report).

Learn supervision and resident evaluation strategies for EOL clinical opportunities.

Plan one new EOL focused clinical experience.

Instructional Design

Demonstrate how to construct teaching objectives for attitudes, knowledge and skill based objectives.

Review the concept of "teaching scripts" used in clinical teaching.

Demonstrate how to develop teaching scripts for three common clinical topics.

Review opportunities for introducing palliative care teaching into different educational settings.

Faculty Development

Understand the barriers and opportunities to faculty education.

Learn how to design a faculty development course.

Plan a faculty development program.

Know at least three ways to build tension for curriculum change.

Understand the two common paths to curriculum change within academic medicine.

DNR, do not resuscitate; EOL, end of life

sessment, including results of the knowledge and confidence surveys. Following the last conference session, residency teams developed a final Action Plan including specific curriculum goals and a 1year timeline of specific tasks and responsibilities. To further support the planning process, each residency was assigned to one project faculty member who met with the residency team at the end of each conference day to review and discuss the residency's evolving strategic plan.

Three months following the conference, the assigned project faculty member telephoned the residency contact and completed a 10-minute structured telephone interview. The project and program faculty reviewed progress toward Action Plan completion and discussed strategies to overcome institutional barriers. Participants were encouraged to contact project faculty mentors or other project faculty at any time to discuss the implementation of their strategic plans. All conference attendees were placed on an e-mail distri- bution list to receive announcements describing professional palliative care development opportunities, teaching tips, and pertinent palliative care education references. In addition, the project disseminated Fast Facts, an educational intervention developed by a physician participant in the project's pilot, presenting short focused palliative care case-based questions and answers. ${ }^{27}$

\section{Project outcome evaluation}

To assess progress at 12 months, program directors were asked to complete a structured report identifying new educational initiatives arising from both the direct training at the workshops and from the educational resource material provided to each residency program. The following domains were sampled in the 12-month progress report: new curriculum content in pain management and non-pain symptom management; new teaching in seven specific palliative care commu- 
nication domains; integration of palliative care into one of three regularly scheduled conferences (grand rounds, morbidity and mortality or morning report); development of new required or elective palliative care or hospice clinical experiences; use of the educational quality improvement projects; and new efforts directed at improving the palliative care knowledge or skills among faculty. Program directors were also asked if they had used any of the five educational resources provided to them and to rate their estimated progress towards completion of their Action Plan goals. Finally, recognizing that this project was occurring at a time of other palliative care educational and system change initiatives, program directors were asked to rate the percentage of new palliative care educational work that they attributed directly to their participation in this project. The survey was mailed and followed by e-mail reminders and a second mailing if there was no response; telephone calls were made to nonresponders encouraging completion.

Some residency programs did not complete the structured 12-month report, but did submit structured progress reports for the 1-day follow-up conference that were subsequently published. The published reports from residency programs that did not complete the structured 12-month report were reviewed for documentation of new curricular, faculty development, and clinical experiences consistent with the questions from the 12-month report. Additional data from mentoring phone calls and ad hoc communication were available for review, but not included in the final outcome analysis as the data was not elicited with methods comparable to the structured 12 month progress reports or published progress reports.

Project cost was calculated by totaling the project grant funding and estimating residency program expenses for conference attendance. An average airfare of $\$ 300$ per attendee was used plus $\$ 50$ in round-trip taxi fare per program. The sole hotel used for conferences offered a package rate for room and all meals of $\$ 229$ per day. No attempt was made to develop a cost analysis for the number of hours spent on new curriculum integration once programs returned to their home institution.

\section{RESULTS}

Three hundred seventy-eight programs filed an initial commitment letter; 20 withdrew prior to the 2-day conference and are not included in the analysis. The 358 evaluable programs included internal medicine $(n=169)$, family medicine $(n=106)$, neurology $(n=39)$ and surgery $(n=44)$, representing, respectively, $47 \%, 22 \%$, $33 \%$, and $17 \%$ of all U.S. residency programs in each specialty or $27 \%$ of all potential programs from the four residencies combined. Residency programs from 49 states and Puerto Rico were represented. The average number of residents from all training years combined, per program, was 33 (range, 6-177). Nine hundred eighty-three faculty and residents attended the 12 two-day conferences (2.7 participants per residency); 219 attendees from 157 programs participated in the 1-day follow-up conferences.

Results of the attendee evaluation of the training conferences indicated that participants' perceived that the educational sessions met their objectives and engaged the participants in curriculum planning; these findings were consistent across the cohorts, replicating the experience that participants reported in the pilot project. ${ }^{17,18}$

Twelve-month reports were completed by 188 programs (53\%); another $36(10 \%)$ submitted progress reports for publication but did not submit a 12-month report. Interim reports from mentoring calls were available from another 26 programs $(7 \%)$ but were not included in the analysis. A lower percentage of residency programs provided follow-up reports or progress reports in neurology (38\%) and surgery programs (45\%) than internal medicine $(67 \%)$ or family practice $(72 \%)$.

The breakdown of integration in four curriculum domains, pain, non-pain symptoms, communication skills and clinical experiences, by specialty, is shown in Figure 1. Over $75 \%$ of all programs reported new curriculum features in pain management and communication skills. In particular, family practice and internal medicine reported the greatest curriculum change; $94 \%$ of internal medicine and $90 \%$ of family practice programs added new content in pain while $83 \%$ of internal medicine and $92 \%$ of family practice added new training in communication skills. Sixty percent or more of internal medicine, family practice, and surgery programs reported new training in non-pain symptoms. Seventy percent or more of internal medicine or family practice programs began new experiential training opportunities while $40 \%$ of neurology and $10 \%$ of surgical programs developed such opportunities. 


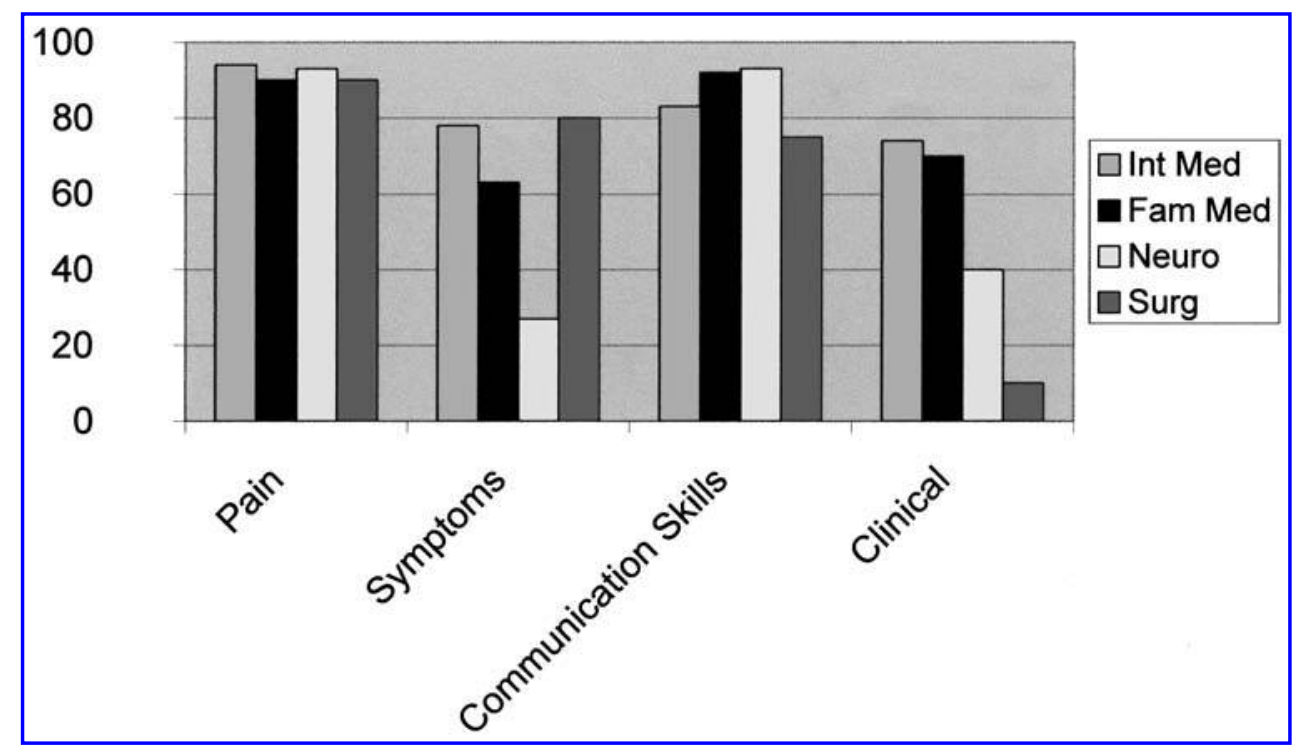

FIG. 1. Percent programs reporting new curriculum elements. Data from 224 programs submitting 12-month follow-up data or a published progress report. Pain, pain assessment and management education; symptoms, non-pain symptom assessment and management education; communication skills, at least one of the following: giving bad news, discussing prognosis or do-not-resuscitate (DNR) orders; running a family conference; discussing hospice referral or completing a spiritual assessment. Clinical, at least one of the following: palliative care elective or required outpatient or inpatient experience, or required or elective hospice home visits.

Figure 2 shows a breakdown of specific communication skills teaching by specialty. Over $50 \%$ of internal medicine and family practice programs started educational training dealing with giving bad news, prognosis, and DNR discussions, goals of care/family conferencing, and hospice referrals. More than $40 \%$ of internal medicine and family practice programs began training in spiritual assessment and provided opportunities for trainee personal reflection. Over $50 \%$ of neurology and surgery programs started new training programs for giving bad news and DNR discussions with lesser penetration of the other communication topics.

Figure 3 provides a breakdown of new required or elective experiential training opportu-

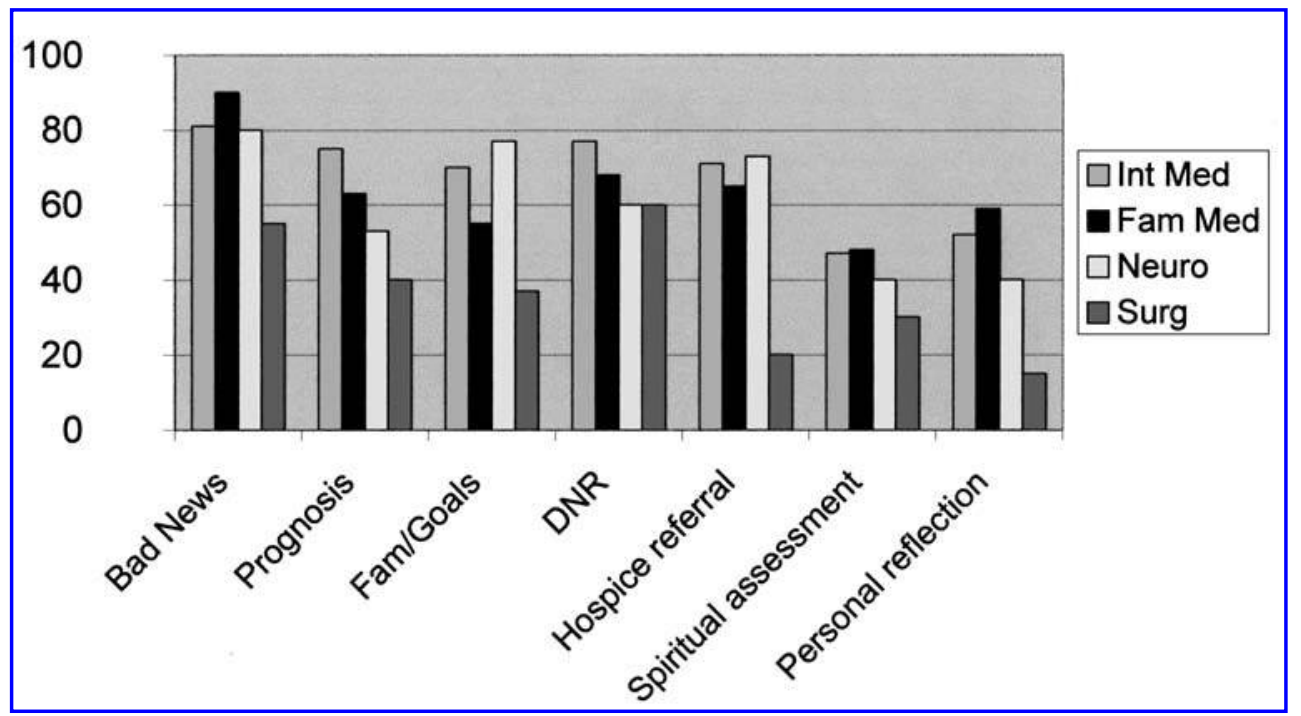

FIG. 2. Percent programs offering new communications education. Data from 224 programs submitting 12-month follow-up data or published progress report. Communication skills training included any element of lecture, small group, or skills training (e.g., objective structured clinical examination [OSCE]). 


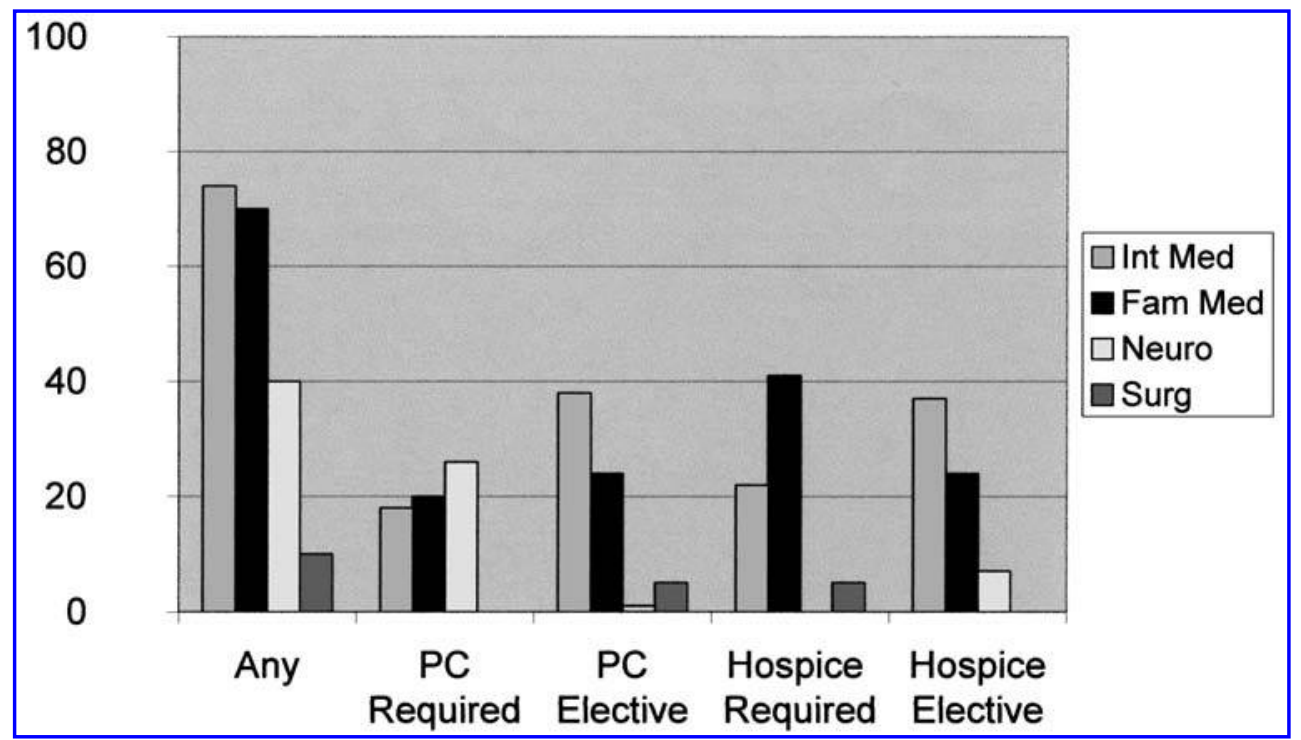

FIG. 3. Pecent programs offering new clinical experiences. Data from 224 programs submitting 12-month follow-up data or published progress report. Any one of the following clinical experiences. PC required, any required outpatient or inpatient palliative care experience. PC elective, any elective outpatient or inpatient palliative care experience. Hospice required, any required hospice home or inpatient hospice experience. Hospice elective, any elective hospice home or inpatient hospice experience.

nities. Over $70 \%$ of internal medicine and family medicine programs began required or elective palliative care or hospice-based clinical experiences for residents while only $40 \%$ of neurology and $10 \%$ of surgery programs began such offerings. The breakdown of adjunctive curriculum features is show in Figure 4. Palliative care content was integrated into existing conferences (grand rounds, morbidity and mortality or morning report) in $67 \%-83 \%$ of programs. Faculty development was initiated in $10 \%-42 \%$ of programs while $20 \%-41 \%$ of programs used at least one

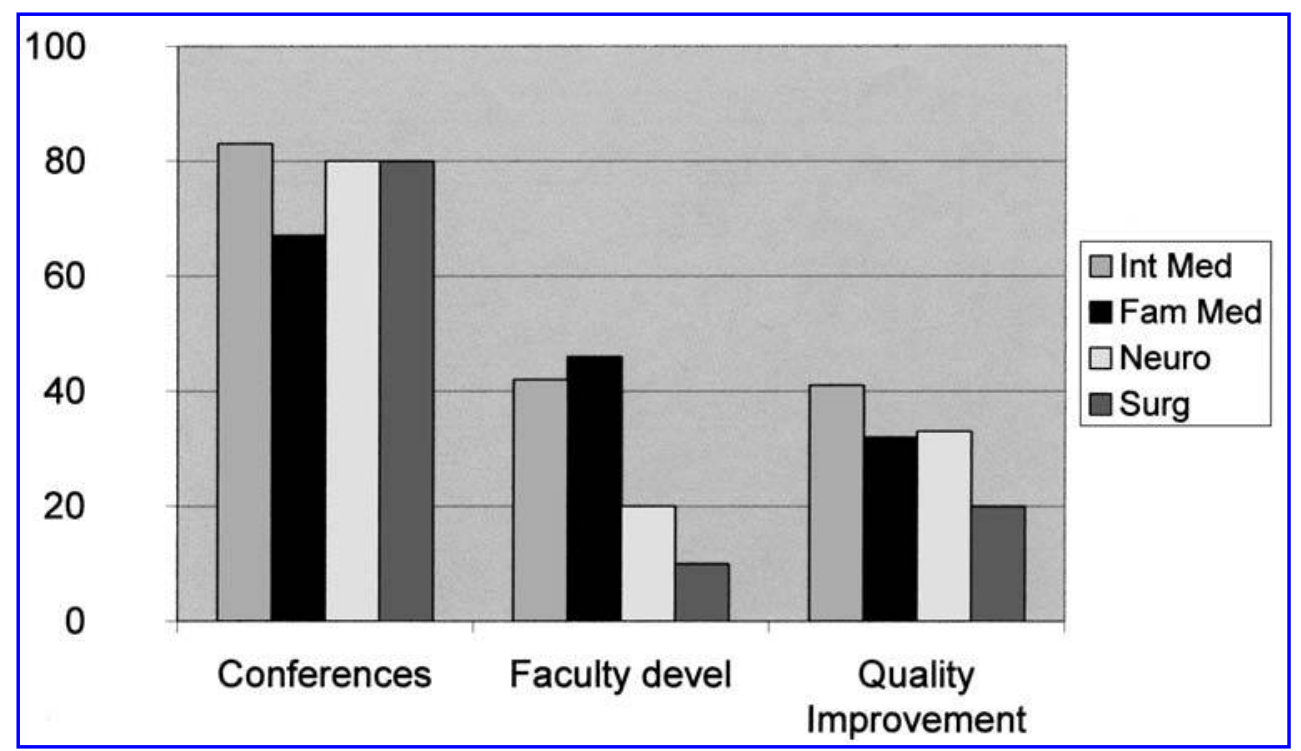

FIG. 4. Percent programs reporting new curriculum adjuncts. Data from 224 programs submitting 12-month followup data or published progress report. Conferences, new inclusion of palliative care content in at least one of the following: grand rounds, morning report, morbidity/mortality conferences. faculty development, any report of faculty training via lecture, workshop or small group work. QI, any use of one of four quality improvement projects: pain assessment, pain management, advance care planning or hospice referral. 


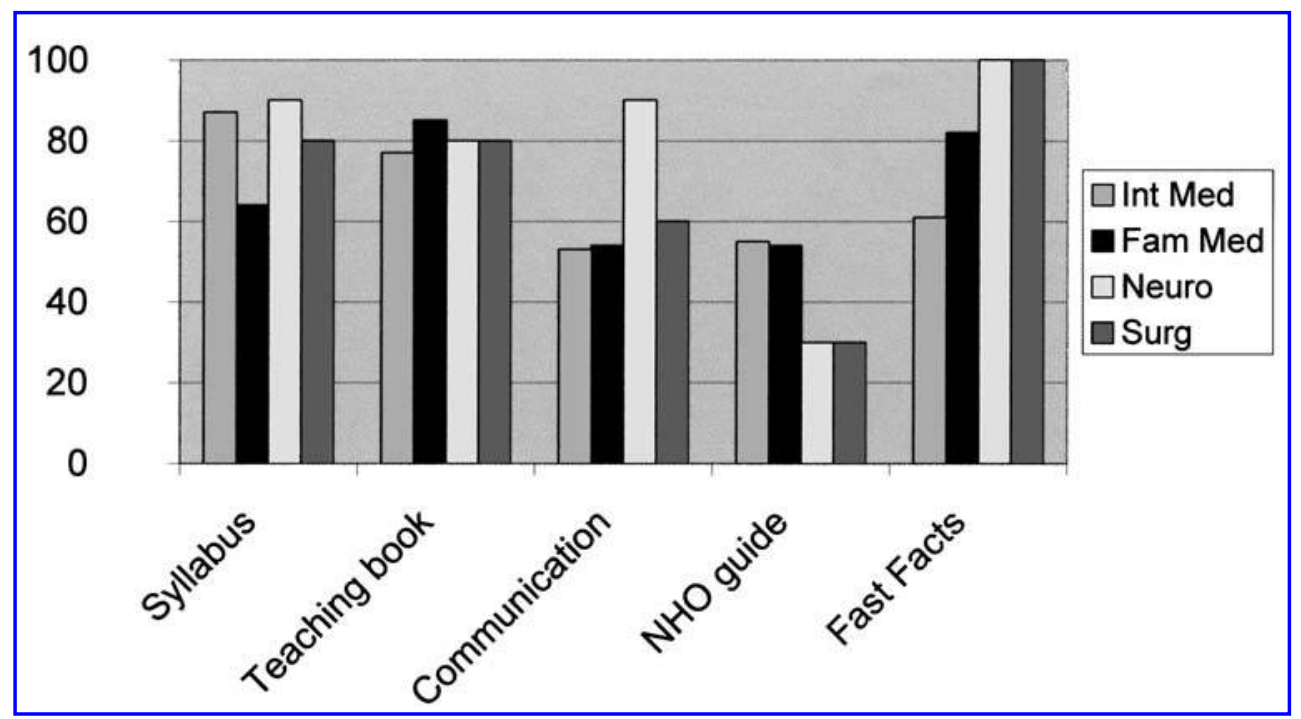

FIG. 5. Percent programs reporting use of educational resource material. Data from 188 programs submitting 12month follow-up data. See Table 2 for description of teaching resource material.

quality improvement project to spur educational change. Among the quality improvement projects, pain and advance care planning projects were used more than the hospice referral project. The educational materials provided to programs were well utilized following the teaching conference, especially the conference syllabus, the resource guide for physician education, and Fast Facts (Fig. 5).

Programs felt they made good progress toward completion of their Action Plan goals with a mean rating of $3.5 \pm 74(1=$ no progress, $5=$ extensive progress). Residencies reported that, on average, they attributed $70 \% \pm 26 \%$ of their progress directly to their participation in this program (internal medicine, $67 \%$; family medicine, $70 \%$; neurology, $92 \%$; surgery, $78 \%$ ).

The total grant support for this project was $\$ 1,353,690$. The estimated total direct costs for each residency to attend the conferences was $\$ 988,015$ making a total project expenditure of $\$ 2,341,705$ or $\$ 6,541$ per residency or $\$ 198$ per resident.

\section{DISCUSSION}

The new medical specialty of palliative medicine is rapidly growing and becoming part of the fabric of medical care and medical education. The past ten years have seen a flurry of physician education activities including new resource material, large-scale physician-education projects, fac- ulty development initiatives, textbook revision projects, and individual medical school and residency curriculum change projects. A national conference on palliative care physician education was held in 1999 from which a series of consensus documents were developed, outlining optimal pedagological approaches within specific educational settings. ${ }^{28-30}$

The aim of this project was to help a diverse group of residency programs apply existing knowledge about best educational practice in palliative care, and to develop and implement new curriculum elements in their training programs. The decision to initiate this project in internal medicine, and then extend it to family medicine, neurology and general surgery programs was based solely on new palliative care training requirements developed by the specialty's residency review committee or by their parent specialty organization. Thus, the development of a new training requirement was the leverage point, the point of educational tension, for curriculum change.

The project intervention and endpoints were designed to move residency programs to adopt a comprehensive approach to curriculum development that would move beyond simply a new palliative care lecture series. First, we wanted programs to adopt new didactic or small group education in the key educational domains where well-documented knowledge deficits exist, namely pain and symptom management. Second, we believed that the attitude, knowledge, and 
skill deficiencies related to doctor-patient communication needed special attention given the central role of and challenging and time-consuming learning process for mastering communication competencies in palliative care. Thus, we devoted one third of the educational contact time in the 2-day workshop to demonstration and discussion of communication skills teaching. Third, we hoped that incorporation of palliative care into routine conferences such as grand rounds, morbidity and mortality conferences, and morning report would enhance the overall palliative care curriculum and demonstrate that palliative care was an appropriate content area, similar to traditional educational content taught in other parts of residency. Fourth, we believed that faculty development was vital for sustainability of palliative care education. Fifth, we believed that clinical palliative care experiences were an essential curriculum component to reinforce didactic and small group teaching and to permit development of clinical skills. Sixth, we hoped that quality improvement techniques could be used as leverage for curriculum change. Finally, we were cognizant that few program directors or resident teaching faculty, especially in the early years of this project, would have the time or expertise to develop new educational materials. To meet this need, we amassed a coherent set of teaching materials that could be directly applied to resident education, including learning objectives, lesson plans, a communication trigger videotape and communications teaching workbook, pocket reference cards, content outlines, and key educational and clinical references.

Project results indicate considerable success in all areas of curriculum development. The easiest curriculum features to incorporate, namely didactic or small group teaching of pain and nonpain symptom management and integration of palliative care into routine large-venue conferences, were added to most training programs. This finding tells us that contrary to popular belief, residency program directors were able to find curricular time for new content when presented with both a rationale for making changes, new training requirement, and with ready-to-use educational resources.

Second, communication skills training, a more teacher-intensive and attitude/skill based educational domain, received more attention than we anticipated. We believe that the combination of two workshops at the 2-day conference, in which exemplar educators provided demonstrations of pedagological techniques combined with readyto-use teaching resources for the program directors, were essential elements of success.

Two of the more labor intensive curriculum features were found in less than $50 \%$ of programs: faculty development and use of quality improvement projects. The fact that any programs began such efforts is encouraging, but much more work than we could provide within the limitations of this project is needed to fully support these ambitious goals. We strongly encouraged participating programs to send one or more faculty to participate in the Harvard Medical School Program in Palliative Care Education and Practice (PCEP), a national faculty development program in palliative care, and Education on Palliative and End-of-Life (EPEC) courses to help drive their local faculty development efforts.

The disparity across specialties in providing follow-up reports was striking, with neurology and surgical programs lagging behind internal medicine and family practice. Observations from the project faculty at the training conferences indicated no major differences among different specialties in project engagement. Although there were small differences between specialties regarding which new curriculum features were adopted, in general there was more similarity than differences. The two areas of greatest difference were in starting new clinical experiences and faculty development. It is not surprising that internal medicine and family medicine began more clinical experiential training, as clinical experiences in palliative care/hospice are well aligned with primary care physician training. The lack of faculty development in neurology and surgery was disappointing and worrisome for long-term sustainability of their new educational programs.

There is little return-on-investment data for complex educational interventions. This project had an estimated cost of approximately $\$ 6500$ per residency program, of which the residency programs themselves contributed $42 \%$ of the cost, another potential motivating force for making curriculum change. When viewed at the level of the resident, the cost was only $\$ 198$ per resident, or roughly equivalent to the price of two to three specialty textbooks. If the reported curriculum changes are sustained beyond one residency cohort and/or lead to other positive changes in institutional culture of caring for seriously ill pa- 
tients, then the return-on-investment becomes greatly magnified.

This project did not utilize a control group to assess curriculum changes for non-participating residencies, thus we do not know to what degree such programs began similar educational initiatives. We tried to assess this information indirectly by asking program directors how much of the new curriculum work was directly attributable to this program; the average attribution of $70 \%$ is an indication that most, but not all, changes resulted from this project. A second limitation was the use of self-report forms for assessing curriculum change. Without some method of externally validating program reporting there is certainly a possibility that program directors under reported or over reported their accomplishments. Of note, the anecdotal experiences of the project faculty were that many programs under reported their progress during mentoring and ad hoc communication. It was common for program directors to verbally indicate that they had not progressed as rapidly as they felt the project faculty were expecting, even when they were making marked progress. This phenomenon, also noted in the pilot project, seems indicative of a positive project faculty-attendee relationship in which the attendee felt a responsibility to meet faculty expectations. A third limitation was the lack of outcome data from $37 \%$ of residencies. In the pilot project, $22 \%$ of programs were lost to follow-up. We anticipated a higher dropout rate following the pilot as a natural evolution of a long term project where there is likely to be less enthusiasm for change among late adopters. Since we have no data on programs lost to follow-up, from a reporting standpoint we can assume only one of two things, either the program did no work or did some work that, for whatever reason, they chose not to report. We do know, based on our experience in the pilot project, that institutional and staffing changes in residency programs commonly occurred that interfered with project work. Some of the confounding problems reported to the faculty included change of program director, change in departmental leadership, or change in hospital finances that impacted faculty responsibilities. Another suspected reason for lack of curriculum change or reporting was a lack of commitment to curriculum change and/or lack of leadership skills by the project team. Finally, a limitation of this project was the 1-year follow-up window; we have no knowledge about the sustainability, expansion, or retrenchment of these new initiatives beyond 12 months.

In summary, this 5-year project represents a first significant attempt to bring the principles of palliative care into a national sample of residency programs. The short-term (12-month) results indicate significant new curriculum work that we hope will be used as a starting point for further curricular development. Other national initiatives, in particular the growth of hospital-based palliative care programs, and the move to formal specialty status, will only serve to further enhance residency education in palliative care.

\section{ACKNOWLEDGMENTS}

The authors would like to thank the staff from American Board of Internal Medicine, American Academy of Neurology, American College of Surgeons, and the Society of Teachers of Family Medicine for their help in residency program recruitment. Lisa-Pelzek Braun, Rose Hackbarth, and Barb Boutot, served as project managers coordinating conference logistics and data management. Special thanks to Alan Carver, M.D. and Wendy Peltier, M.D. for help in designing the neurology curriculum. Finally, thanks to Rosemary Gibson and The Robert Wood Johnson Foundation for continued support of this project.

The project was supported by grants from The Robert Wood Johnson Foundation.

\section{REFERENCES}

1. Field MJ, Cassel CK (eds): Approaching Death: Improving Care at the End of Life. Report from the Institute of Medicine Committee on Care at the End of Life. Washington, D.C.: National Academy Press, 1997.

2. Block SD, Sullivan AM: Attitudes about end-of-life care: a national cross-sectional study. J Palliat Med 1998;1:347-55.

3. Sullivan AM, Lakoma MD, Block SD: The status of medical education in end-of-life care: A national report. J Gen Intern Med 2003;18:685-695.

4. Billings JA, Block S: Palliative care in undergraduate medical education. Status report and future directions. JAMA 1997;278:733-738.

5. Weissman DE, Block SD: ACGME requirements of end-of-life training in selected residency and fellowship programs: A status report. Acad Med 2002;77: 299-304. 
6. Ogle KS, Mavis B, Thomason C: Learning to provide end-of-life care: Postgraduate medical training programs in Michigan. J Palliat Med 2005;8:987-997.

7. Egnew TR, Mauksch LB, Greer T, Farber SJ: Integrating communication training into a required Family Medicine Clerkship. Acad Med 2004;79:737-743.

8. DeVita MA, Arnold RM, Barnard D: Teaching palliative care to critical care medicine trainees. Crit Care Med 2003;31:1257-1262.

9. Fins JF, Nilson EG: An approach to educating residents about palliative care and clinical ethics. Acad Med 2000;75:662-665.

10. Serwint JR, Rutherford LE, Hutton N, Rowe PC, Barker S, Adamo G: "I learned that no death is routine": Description of a death and bereavement seminar for pediatrics residents. Acad Med 2002;77:278284.

11. Liao S, Amin A, Rucker L: An innovative longitudinal program to teach residents about end-of-life care. Acad Med 2004:79:752-757.

12. Hallenbeck JL, Bergen MR: A medical resident inpatient hospice rotation: experiences with dying and subsequent changes in attitudes and knowledge. I Palliat Med 1999;2:197-208.

13. Fischer SM, Gozansky WS, Kutner JS, Chomiak A, Kramer A: Palliative care education: An intervention to improve medical residents' knowledge and attitudes. J Palliat Med 2003;6:391-399.

14. von Gunten CF, Mullan PB, Harrity S, Daimant J, Heffernan E, Ikeda T, Roberts WL; Faculty, Center for Pallative Study: Residents form five training programs report improvements in knowledge, attitudes and skills after a rotation with a hospice program. I Cancer Educ 2003;18:68-72.

15. Ross DD, Shpritz D, Alexander CS, Carter K, Edelman MJ, Friedley N, Hemani A, Keay TJ, Roy SC, Silverman H, Tasker DJ, Timmel D, Schwartz J, Wolfsthal SD: Development of required post graduate palliative care training for internal medicine residents and medical oncology fellows. I Cancer Educ 2004; 19:81-87.

16. Han PKJ, Keranen LB, Lescisin DA, Arnold RM: The palliative care clinical evaluation exercise (CEX): An experience-based intervention for teaching end-of-life communication skills. Acad Med 2005;80:669-676.

17. Mullan PB, Weissman DE, Ambuel B, von Gunten CF. End-of-life care education in internal medicine residency programs: an inter-institutional study. I Palliat Med 2002;5:487-496.

18. Weissman DE, Mullan PB, Ambuel B, von Gunten CF: End-of-life curriculum reform: Outcomes and impact in a follow-up study of Internal Medicine residency programs. J Palliat Med 2002:5:497-505.
19. American Medical Association, Graduate Medical Education Directory. 〈www.ama-assn.org/ama/pub/ category/3991.html\#1) (Last accessed February 16, 2007).

20. Weissman DE, Ambuel B, Norton A, Wang-Cheng R, Schiedermayer D: A survey of competencies and concerns in end-of-life care for physician trainees. I Pain Symptom Manage 1998;15:82-90.

21. Von Gunten CF: Interventions to manage symptoms at the end of life. I Palliat Med 2005;8(Suppl 1) S88-94.

22. Mullan PB, Weissman D, von Gunten C, Ambuel B, Hallenbeck J: Coping with certainty: Perceived competency vs. training and knowledge in end of life care. J Gen Intern Med 2000;15:40(suppl):40.

23. Weissman DE, Mullan P, Ambuel B, et al. Improving end-of-life care: Internal medicine curriculum project: Project abstracts/Progress report. J Palliat Med 2001; 4:75-102.

24. Weissman DE, Mullan P, Ambuel B, von Gunten CF, Block S: Improving end-of-life care: Internal medicine curriculum project: Project abstracts / progress report. J Palliat Med 2002;5:579-606.

25. Weissman DE, Mullan P, Ambuel B, et al. Improving end-of-life care: Internal medicine curriculum project: Project abstracts/progress report. I Palliat Med 2003; 6:941-964.

26. Weissman DE, Mullan P, Ambuel B, et al. Improving end-of-life care: Internal medicine curriculum project: Project abstracts/progress report. I Palliat Med 2005; 8:646-664.

27. Warm E: Fast Facts and Concepts: An educational tool. J Palliat Med 2000;3:332-333.

28. Block S: National consensus conference on medical education for care near the end of life: Executive summary. J Palliat Med 2000;3:88-92.

29. Weissman DE, Block SD, Blank L, Cain J, Cassem N, Danoff D, Foley K, Meier D, Schyve P, Theige D, Wheeler HB: Incorporating palliative care education into the acute care hospital setting. Acad Med 1999;74: 871-877.

30. Block SD, Bernier GM, Crawley LM, Farber S, Kuhl D, Nelson W, O’Donnell J, Sandy L, Ury W: Incorporating palliative care into primary care education. I Gen Intern Med 1998;13:768-773.

Address reprint requests to: David E. Weissman, M.D. Froedtert Hospital 9200 West Wisconsin Avenue Milwaukee, WI 53226

E-mail: dweissma@mcw.edu 
This article has been cited by:

1. Aaron M. Olden, Timothy E. Quill, Donald Bordley, Susan Ladwig . 2009. Evaluation of a Required Palliative Care Rotation for Internal Medicine ResidentsEvaluation of a Required Palliative Care Rotation for Internal Medicine Residents. Journal of Palliative Medicine 12:2, 150-154. [Abstract] [PDF] [PDF Plus]

2. Charles F. von Gunten . 2007. Signs of LifeSigns of Life. Journal of Palliative Medicine 10:2, 280-280. [Citation] [PDF] [PDF Plus] 